ISSN 1112-9867

http://www.jfas.info

\title{
A STUDY ON EFFECTS OF CASTLING ON NATURAL FREQUENCIES OF 3D UN- DAMPED STEEL FAMES USING FINITE ELEMENT METHOD
}

\author{
M. Bagheri ${ }^{1}$, S. Baharom ${ }^{2}$, M. Izadi Niaki ${ }^{3}$ \\ ${ }^{1}$ M.Sc. graduate, Dept. of Civil Engineering, National University of Malaysia, UKM, Malaysia \\ ${ }^{2}$ Professor, Department of Civil \& Structural Engineering, National University of Malaysia, \\ Malaysia \\ ${ }^{3}$ M.Sc. graduate, Dept of Civil Engineering, Shiraz University, Shiraz, Iran
}

Published online: 15 February 2017

\begin{abstract}
The effects of castling on natural frequencies in 3D steel frames were investigated in this study since accurate assessment of fundamental period (frequency) of a structure is an essential part of design and analysis processes. The use of LUSAS 14.03 was adopted to calculate free vibration characteristics of frames. Thin shell element was used to modeling frames. The initial results are verified by Cinitha.A, Rama Raju. K \& Nagesh.R. Iyer (2008) and hand calculations using UBC code.. Furthermore different parameters such as Number of stories, Height of frames, Percentage of Castling, stiffness of connections and Supports Conditions were considered in order to evaluate their effects in frame modal respond. The results of above investigation show that by increasing the percent of castling the natural frequency will increase. Also by reduction of connection rigidity fundamental frequency will reduce. In order to achieve effective earthquake design we also have to consider these two parameters. Finally some suggestions were made in order to improve steel design against earth quake effects.
\end{abstract}

Author Correspondence, e-mail: author@gmail.com

doi: http://dx.doi.org/10.4314/jfas.v8i2s.672 


\section{INTRODUCTION}

Properly designed, steel frames are very efficient in resisting forces generated from ground motion because of their ability to dissipate seismic energy through large inelastic deformation and damping. So steel is often used for buildings in seismically active regions. Beside nowadays construction of light buildings is common so it is important to study the behavior of high-raised building under self and dynamic loads [1]. The design of steel structures subjected to natural hazards such as earthquakes demands safety of structures which is governed by the fundamental frequency and the magnitude of frame response. Reasonably accurate assessment of these characteristics is an essential part of design and analysis processes [2]. These days trend to usage of castled sections in steel frames is increasing since using castled beams makes the building lighter and more economical. So by considering the importance of periods of building it is necessary to study the effect of castling on natural frequencies of steel frames. In this study the effect of castling on dynamic characteristics of the Space Frame such as fundamental frequency and natural periods of the building are considered[3]. Also the effect of frame height as well as number of stories has been considered. Effect of connection rigidity and percentage of castling on fundamental frequency of steel frames also studied. Majority of structural soft wares can evaluate the natural frequencies of frames using their default beam and column profiles same as standard I sections or Wide Flanges in a fraction of second, but most of these soft wares does not have arbitrary castled sections which designer wants to apply in structure[4]. Also when designer wants to calculate the natural period of steel frame using codes and hand calculation, determining the natural frequency of castled steel frame which is key element of seismic and dynamic design of frame is time taking in comparison with non-castled section[5]. Since calculation of exact value of moment of inertia (I) for castled beams in order to obtain natural periods is not easy and using FEM is compulsory to evaluate the natural periods of castled frames, proposing an equation based on various FE analysis can be useful. In this study

- Effect of castling on Moment Resistance Frames

- Effect of castling on Semi-Rigid Frames

For various numbers of stories, frame heights plan ratios and connection rigidities will be considered. 


\section{MOMENT RESISTANCE STEEL FRAMES}

Laurai and Valerga (1987) have investigated the vibrating frames carrying concentrated masses, and in-plane vibrations of portal frames with end supports, elastically restrained against rotation and translation by using analytical and numerical method. The natural frequencies and mode shapes for the in-plane vibration of triangular closed and planar frames have been studied by using the Rayleigh-Ritz method They assumed frames are 2D and the weight of entire story is concentrated at center of ceiling beam[6]. The advantage of their assumption is simplicity of model and using Rayleigh-Ritz method easily but the disadvantage is that the effect of castling cannot be calculated in models since the model is assumed by lumped mass. Cinitha and Rama (2008) have Evaluated Free Vibration Characteristics of Steel Space Frames. In their paper they used Small-scale (1:15) model for experimental analysis. The numerical results of the model were compared with the experimental results [7]. Numerical studies are extended to find the influence of the plan and bay dimensions, normalized stiffness, height of stories, on the fundamental frequency of the moment resisting frames. They have found that the fundamental frequency decreases with increase in height of the building irrespective of plan dimensions of the building. It is also found that the variation in fundamental frequency is not much significant with increase in plan ratio. They have considered rigid connections and non-castled section in their study. Effect of castling, plan ratio and height of stories did not evaluate simultaneously [8]. Most of the building codes provide empirical formulae that depend on the building material (steel, reinforced concrete, etc.), building type (frame, shear wall, etc. and overall dimensions but does not give much information about the geometry and symmetry of the building) Cinitha.A and Rama Raju. K (2008). Numerical studies are carried out to study the effect of the plan ratio, castling and connection rigidity on the fundamental frequency. Studies are carried out with different frame configurations

Miodrag Sekulovic and Ratko Salatic (2002) have worked on effects of flexibility and damping in the nodal connections on the dynamic behavior of plane steel frames. The effects of viscous and hysteretic damping on dynamic response of frame structures are taken into consideration. The complex dynamic stiffness matrix for the beam with flexible connections and linear viscous dampers at its ends is obtained. Several examples are included to illustrate the efficiency and accuracy of the present model[9]. 
J. Kent Hsiao (2009) worked on hand-calculated approach for the computing frame deflections using Method $B$ which is specified in the 1997 Uniform Building Code Static. Force Procedure. The general stiffness matrix of a three-story, three-bay frame was used as an aid to compute the deflections for any moment frame within three stories in height and within three bays in width. A hand-calculated static approach, is proposed in his paper to serve as a convenient tool that can be used along with the ASCE/SEI 7-05 Equivalent Lateral Force Procedure to perform both the preliminary design and the final design of low-rise moment frames[10].

His paper just covered rigid connection frames, but the effect of non-rigidity on connection was not imposed in his calculations.

Masih Izadi Niaki et al. conducted a study entitled "OPTIMUM DESIGN OF 2-D REINFORCED CONCRETE FRAMES USING A GENETIC ALGORITHM" and stated that Construction of concrete structures involves at least three different materials: concrete, steel and formwork. A large number of parameters, therefore, have to be dealt with in proportioning a reinforced concrete element, including width, depth, number and diameter of rebar. Consequently, together with experience, trial and adjustment are necessary in the choice of concrete sections. A trial section has to be chosen for each critical location in a structural system. The trial section has to be analyzed to determine if its nominal resisting strength is adequate to carry out the applied factored loads. Since more than one trial is often necessary to arrive at the required section, this process is time consuming. Also, the final design of a practiced designer is different from that of a beginner and it is never known whether the result is an optimum design. The objective of this research is to design optimally reinforced concrete frames that satisfy the limitations and specifications of the American Concrete Institute (ACI) Building Code and Commentary using a Genetic Algorithm (GA). The GA used in this study has an adaptive penalty function. New options are added to the GA, including tournament selection with specified conditions or repairing operator that acts on beams and columns to accelerate convergence of the program. Design results show that the algorithm presented here compares advantageously with classic methods or other GA algorithms used previously for optimum design of concrete frames[11]. 


\section{MODELLING AND ANALYSIS}

As mentioned in chapter 3 varieties of models were tested in order to reach behavior of the building after castling. Table 4.1shows this variation. The fames up to seven stories where modeled, using different bay ratios, story heights connection type as shown in table below. The steps of creating the models already have given in chapter 3 . Figure 4.2

Table 4.1. Variation of models characteristics

\begin{tabular}{llllllll}
\hline Beams & Columns & $\begin{array}{l}\text { No of } \\
\text { Stories }\end{array}$ & $\begin{array}{l}\text { No of } \\
\text { Bays }\end{array}$ & $\begin{array}{l}\text { Story } \\
\text { Height } \\
\text { (m) }\end{array}$ & $\begin{array}{l}\text { Connection } \\
\text { Type }\end{array}$ & $\begin{array}{l}\text { Percentage } \\
\text { Of } \\
\text { castling }\end{array}$ & $\begin{array}{l}\text { Studied } \\
\text { modes }\end{array}$ \\
\hline W24x80 & W18x50 & 1 to 7 & $3 \times 3$ & 3 and 5 & Rigid & $19,38,49 \%$ & $1-2-3$ \\
& & 1 to 7 & $3 \times 1$ & 3 and 5 & Rigid & $19,38,49 \%$ & $1-2-3$ \\
& & 1 to 7 & $1 \times 1$ & 3 and 5 & Fixed and & $19,38,49 \%$ & 1 \\
& & & & & semi-rigid & & \\
\end{tabular}

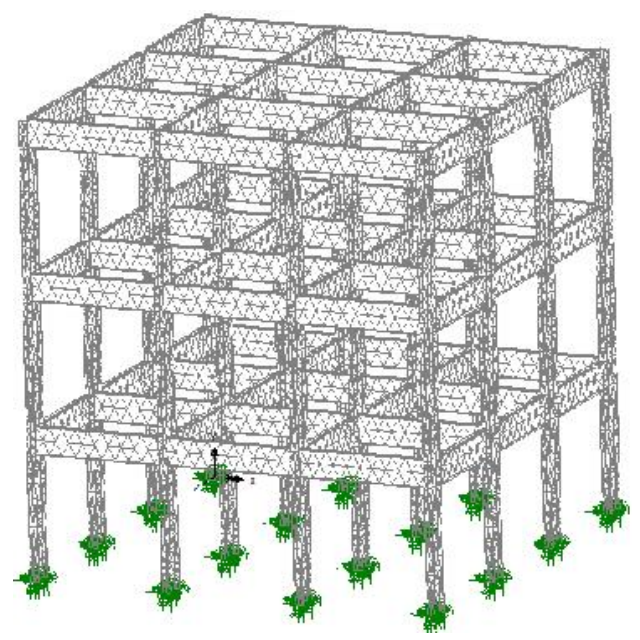

Fig.4.2. Sample of Modeled Frame

\section{ELASTIC CONNECTION MODEL DESCRIPTION}

This stage has divided into three parts which is step by step setting the elastic connection properties of semi-rigid frames. Clearly for MRF this stage is not necessary. Three steps mentioned are as bellow: 
- Define point mesh

- Define joint space

- Define connection stiffness

\section{Define Point Mesh}

Using springs JL46 from LUSAS mesh library. JL46 is 3D joint elements which connects two nodes by six springs in the local $\mathrm{x}, \mathrm{y}$ and $\mathrm{z}$-directions. Use JL46 for semi-loof beam end nodes. Figure 4.7 shows JL46 settings

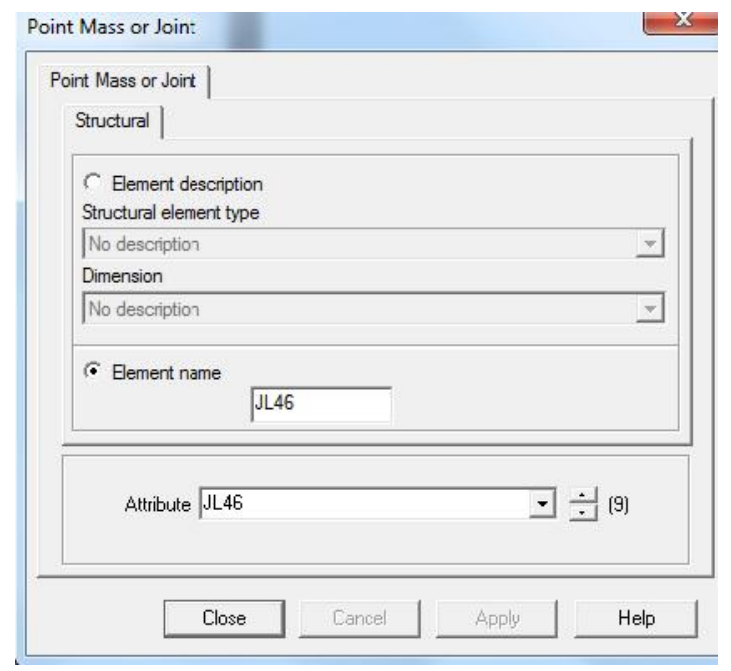

Fig.4.7. Eigenvalue Window settings

Define Joint Space

Geometric joint should be defined in semi-rigid models in order to create a space between to nodes which are going to be connected to each other by a spring. Figure 4.87 shows joint space as $22 \mathrm{~mm}$ which is used in semi-rigid frames.

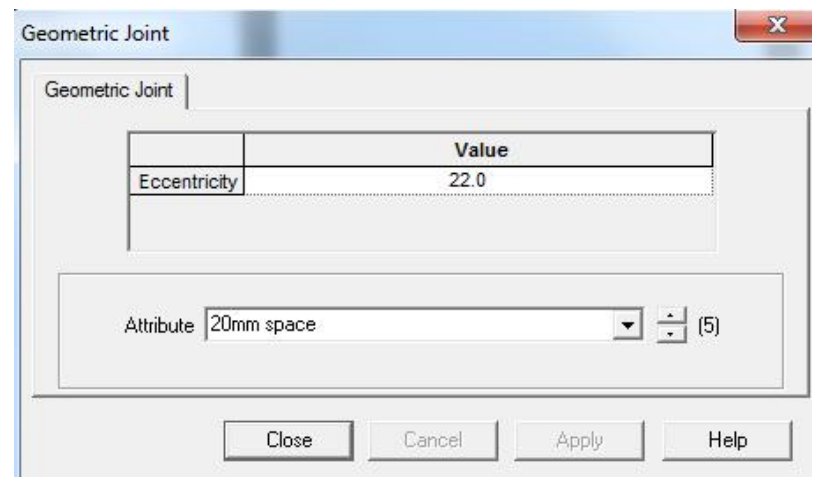

Fig.4.8. Semi-rigid joint spaces 
Define Connection Stiffness

All stiffness properties in connections should be inserted to LUSAS in Material/Attribute/Joints. As figure 4.8 shows Joint Type is chosen Spring Stiffness only by increasing the membrane stiffness First mode frequency increases. In order to study the effect of castling in semi-rigid frames finding proper value of stiffness is needed Series of tests were established to demining the best value of rigidity in which the frequency of frame is almost the same with rigid connection model.

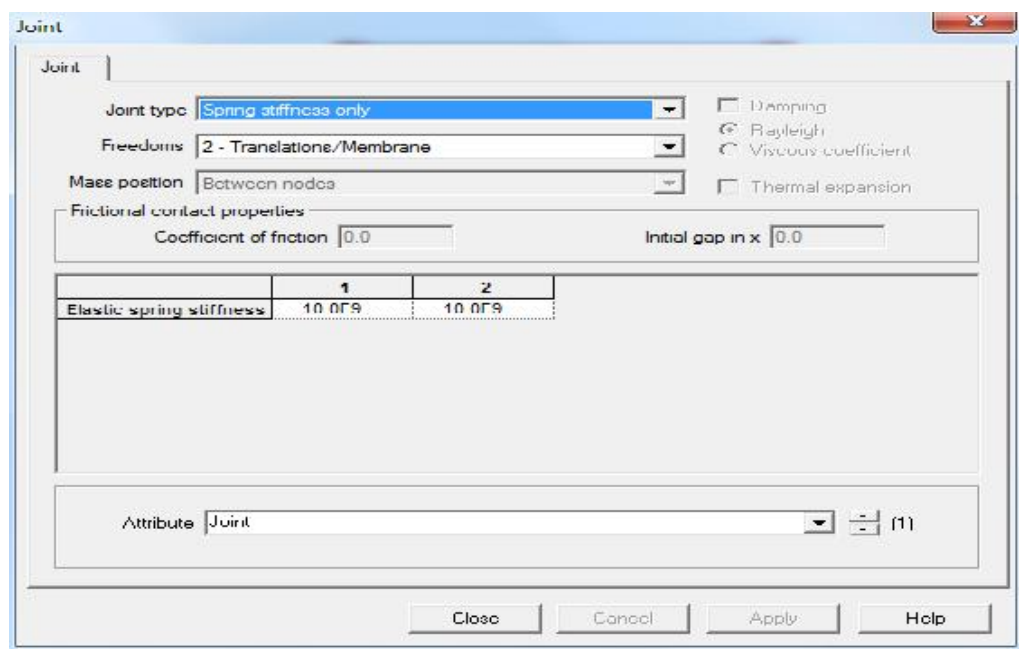

Fig.4.9. Joint stiffness settings in semi rigid frames

\section{CONVERGANCE STUDY}

Convergence Study simply means to increase the number of meshes in FE model in order to make the results more accurate. When by increasing mesh numbers, results stay constant (by certain accuracy) we can say convergence happened. In all FE analysis convergence study is a necessary step to achieve the final answer.

In order to define a certain level of accuracy in convergence procedure in this study, slope of convergence curve has monitored. The slope of convergence curve has defined by equation 4.1.

$\% S=\frac{f_{i}-f_{i-1}}{(\text { element.No })_{i}-(\text { element.No })_{i-1}} \times 100,000$

Equation 4.1 slope of convergence curve

Which: 
$\% \mathrm{~S}$ is slope of convergence curve

$f_{i}$ is frequency which is calculated in step $\mathrm{i}$

$f_{i-1}$ is frequency which is calculated in step i-1

\section{Convergence of 1:15 model}

For example for 1:15 experimental model as described by Cinitha.A and Rama Raju (2008) modeled in LUSAS and the convergence study was run. Figure 4.10 shows model dimensions (all in $\mathrm{mm}$ ). The fundamental frequency of a small model were analyzed to evaluate the effect of castling on short frames, since total height of this mini model is around 1 meter; it can help to find general difference in frequencies in castled and non-castled frames. The model is a 15 times smaller than the full scale model of a three-story single bay moment resisting frame (as figure 4.10). In order to get more data about its period one more story was added on it. This model designed for gravity and seismic loads for zone III as per IS 800(1984) and IS 1893 (2002) with moment resistance welded and bolted connection as Cinitha.A and Rama Raju (2008) Yield stresses, ultimate stress, Modulus of Elasticity of the steel and percentage elongation used are $204.52 \mathrm{~N} / \mathrm{mm} 2,294.20 \mathrm{~N} / \mathrm{mm} 2,2 \times 105 \mathrm{~N} / \mathrm{mm} 2$ and 21.8 respectively. The channels are fabricated from $1.5 \mathrm{~mm}$ thick steel sheets bent by press braking process, which are spot welded back to back and fabricated as I sections for columns and beams.

Table 4.2. Specifications of small I beams and columns.

\begin{tabular}{lllll}
\hline Type & $\begin{array}{l}\text { Flange } \\
\text { width }(\mathrm{mm})\end{array}$ & $\begin{array}{l}\text { Flange } \\
\text { Thickness }(\mathrm{mm})\end{array}$ & $\begin{array}{l}\text { Total } \\
\text { height }(\mathrm{mm})\end{array}$ & $\begin{array}{l}\text { Web } \\
\text { Thickness }(\mathrm{mm})\end{array}$ \\
\hline Beam & 18 & 1.5 & 28 & 3.0 \\
Column & 21 & 1.5 & 21 & 3.0 \\
\hline
\end{tabular}




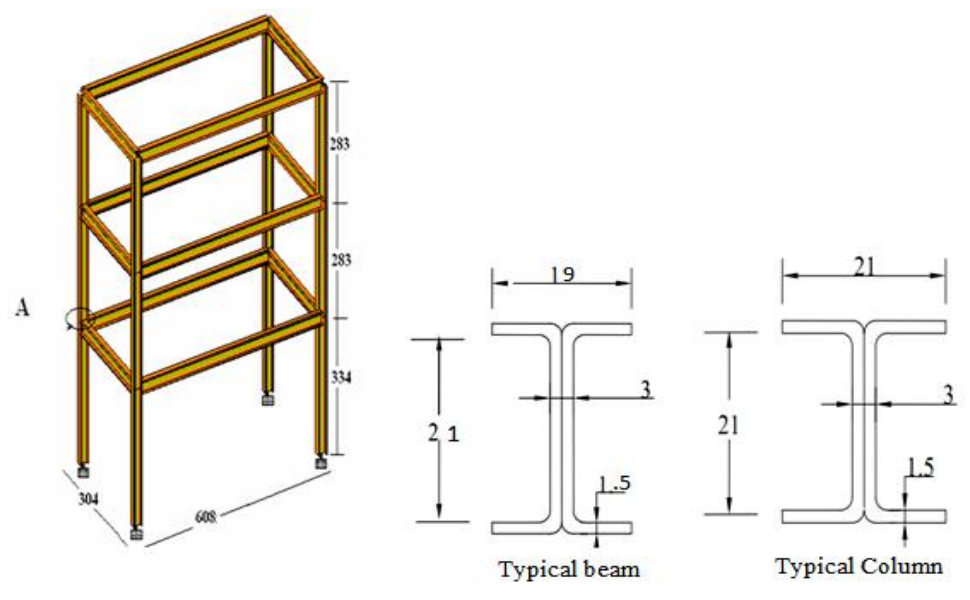

Fig.4.10. Dimensions and Details of 1:15 model

Cinitha.A and Rama Raju (2008)

As shown in figure 4.11 the results of analysis of 1:15 for different element sizes (as described in 4.3 ) is given. Equivalent number of mesh in each step is calculated by LUSAS after applying meshes to surfaces.

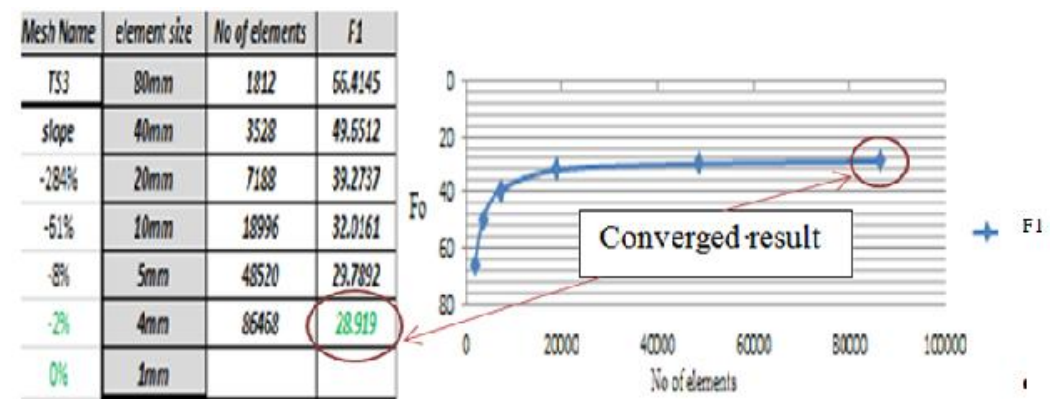

Fig.4.11. Convergence study of 1:15 model

In table represented in figure 4.11 it is can be seen that by increasing the number of elements $\mathrm{F} 1$ which is first mode frequency or fundamental frequency converges. It is obvious that by element size $20 \mathrm{~mm}$ as 7188 elements frequency obtained as $39.2737 \mathrm{~Hz}$, while in last stage, using element size $40 \mathrm{~mm}$ with 3528 elements, the frequency was $49.6512 \mathrm{~Hz}$. The slope was calculated using equation 4.1.If the slope comes less than $3 \%$ the accuracy will be accepted and calculated frequency will be final result of the analysis. This level of frequency happens when in two continuous stage of analysis results are constant by accuracy of 1.0E-4.

Convergence of Full Scale Model 
Another example of convergence study is the analysis of full scale models as described in table 4.1which are main part of this study.

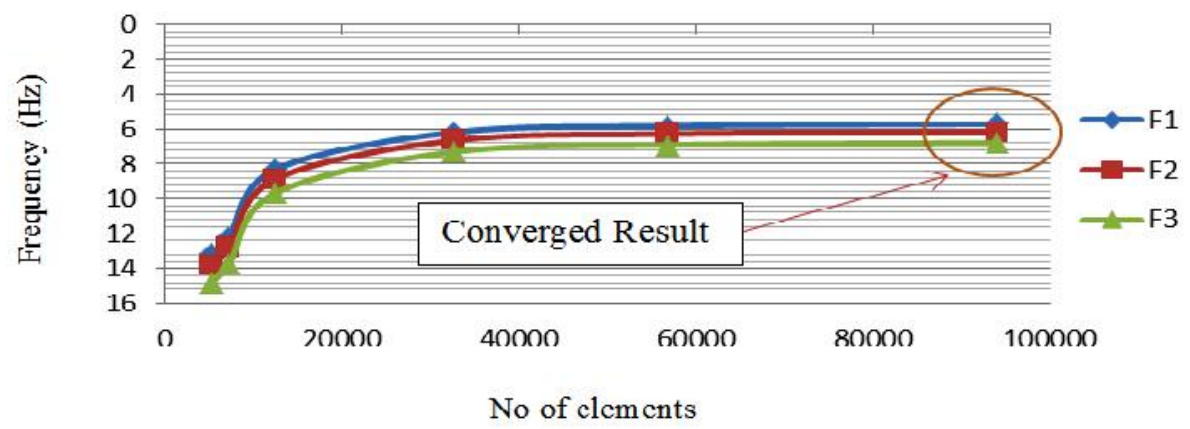

Fig.4.12. Convergence study of experimental model

One Story 3x3Span (story height: $3000 \mathrm{~mm}$ )

Table 4.3. Convergence Study of Full Scale Model One Story 3x3Span (Story Height 3m)

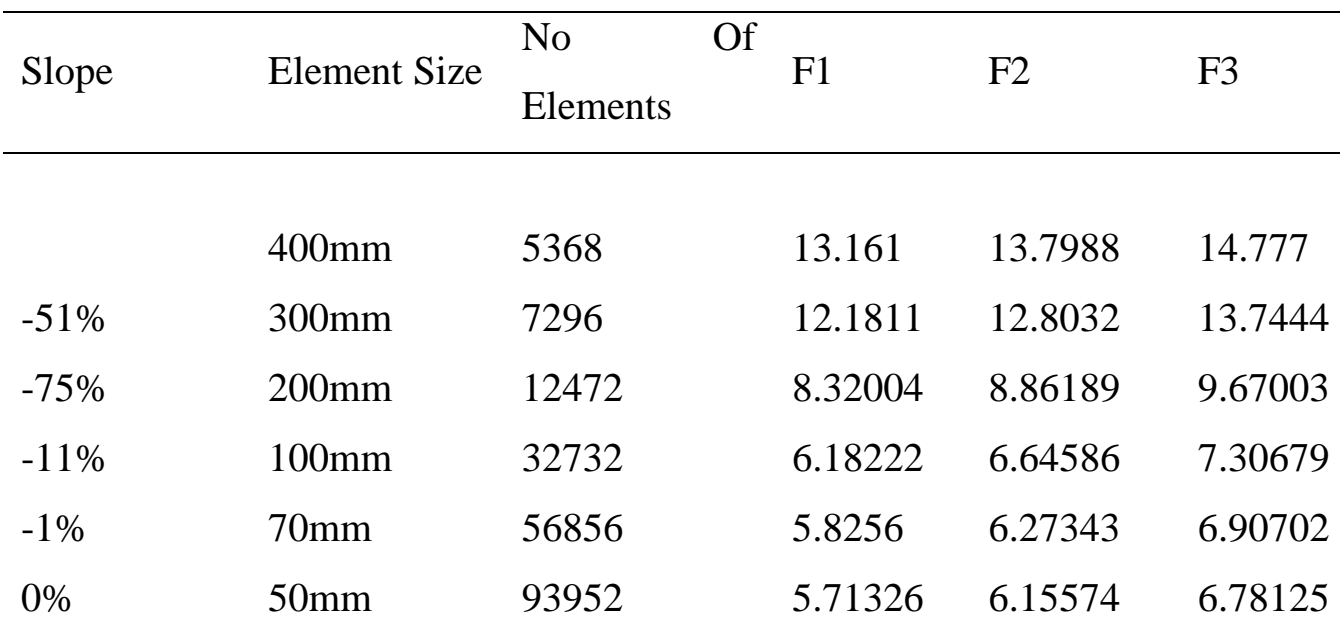

As we can see in Table 4.3 in last row sloe of convergence curve turned to zero so we can stop analysis and accept the results. More convergence examples are given in appendix II.

\section{Convergence of Connection Rigidity}

Moment Resistance Steel frames was fabricated from mild steel plates of different thickness. In this simulation, steel beams and columns are modeled using ungraded Mild Steel in LUSAS material library. The material properties of steel were specified using elastic range. Ungraded Mild Steel which has Young's Modulus equal to $209 \mathrm{kN} / \mathrm{mm}^{2}$ and Poisson's ratio of 0.3. As explained in section 4.7.4 to define a semi-rigid connection we must spring connection rigidity in Joint Stiffness Settings. To determining the best relation between S1 and S2 as shown figure 
4.9 series of models where analyzed using different amounts of rigidities.

Table 4.4 shows different characteristics and dimensions of Semi-Rigid model.

Table 4.4. variation of Semi-Rigid models characteristics

\begin{tabular}{llllllll}
\hline Beams & Columns & $\begin{array}{l}\text { No of } \\
\text { Stories }\end{array}$ & $\begin{array}{l}\text { No } \\
\text { of } \\
\text { Bays }\end{array}$ & $\begin{array}{l}\text { Story } \\
\text { Height } \\
(\mathrm{m})\end{array}$ & $\begin{array}{l}\text { Connection } \\
\text { Type }\end{array}$ & $\begin{array}{l}\text { Percentage } \\
\text { Of }\end{array}$ & $\begin{array}{l}\text { Studied } \\
\text { modes }\end{array}$ \\
\hline W24x80 & W18x50 & 1 to 4 & $1 \times 1$ & $3 m$ & $\begin{array}{l}\text { Rigid/Semi- } \\
\text { Rigid }\end{array}$ & $19,38,49 \%$ & 1 \\
& & & & & & &
\end{tabular}

To evaluate the best relation between $\mathrm{S} 1$ and $\mathrm{S} 2$ as shown in tables 4.5 and 4.6 and figure 4.13, initially S1 was kept constant and then S2. In first case by reducing S2 and in second case by reducing S1 by considering accuracy and frequency the results of analysis where ridden. The aim was to find the relation between S1 and S2 which gives minimum error or maximum accuracy so $\mathrm{S} 1$ and S1 were chosen as a big value so we could be sure that rigidity is big enough for convergence.

Table 4.5. Two Story $3 x 3$ Span Spring Connection (Story Height:3m)

\begin{tabular}{|c|c|c|c|c|c|c|}
\hline S1(N.mm) & S2(N.mm) & $\mathrm{S} 1 / \mathrm{S} 3$ & $\mathrm{~F} 1(\mathrm{~Hz})$ & Error & Rigid F1(Hz & \%Difference \\
\hline $1.00 \mathrm{E}+15$ & $1.00 \mathrm{E}+09$ & 1000000 & 2.71213 & $3.27 \mathrm{E}-01$ & $2.75 \mathrm{E}+00$ & 1.31 \\
\hline $1.00 \mathrm{E}+14$ & $1.00 \mathrm{E}+09$ & 100000 & 2.70922 & 3.09E-02 & $2.75 \mathrm{E}+00$ & 1.42 \\
\hline $1.00 \mathrm{E}+13$ & $1.00 \mathrm{E}+09$ & 10000 & 2.70873 & $2.62 \mathrm{E}-03$ & $2.75 \mathrm{E}+00$ & 1.43 \\
\hline $1.00 \mathrm{E}+12$ & $1.00 \mathrm{E}+09$ & 1000 & 2.70868 & $2.47 \mathrm{E}-04$ & $2.75 \mathrm{E}+00$ & 1.44 \\
\hline $1.00 \mathrm{E}+11$ & $1.00 \mathrm{E}+09$ & 100 & 2.70868 & $2.48 \mathrm{E}-05$ & $2.75 \mathrm{E}+00$ & 1.44 \\
\hline $1.00 \mathrm{E}+10$ & $1.00 \mathrm{E}+09$ & 10 & 2.70868 & $2.75 \mathrm{E}-07$ & $2.75 \mathrm{E}+00$ & 1.44 \\
\hline $1.00 \mathrm{E}+09$ & $1.00 \mathrm{E}+09$ & 1 & 2.70868 & 2.33E-07 & $2.75 \mathrm{E}+00$ & 1.44 \\
\hline $1.00 \mathrm{E}+08$ & $1.00 \mathrm{E}+09$ & 0.1 & 2.70864 & 2.22E-07 & $2.75 \mathrm{E}+00$ & 1.44 \\
\hline $1.00 \mathrm{E}+07$ & $1.00 \mathrm{E}+09$ & 0.01 & 2.70822 & $2.76 \mathrm{E}-07$ & $2.75 \mathrm{E}+00$ & 1.45 \\
\hline
\end{tabular}


Table 4.6. Two Story $3 \times 3$ Span Spring Connection (Story Height:3m)

\begin{tabular}{lllllll}
\hline S1(N.mm) & S2(N.mm) & S1/S4 & Fr(Hz) & Error & \multicolumn{2}{l}{ Rigid F1(Hz) } \\
\hline $1.00 \mathrm{E}+07$ & $1.00 \mathrm{E}+14$ & 0.0000001 & 2.71438 & $3.14 \mathrm{E}-02$ & $2.75 \mathrm{E}+00$ & 1.23 \\
$1.00 \mathrm{E}+07$ & $1.00 \mathrm{E}+13$ & 0.000001 & 2.7141 & $2.44 \mathrm{E}-03$ & $2.75 \mathrm{E}+00$ & 1.24 \\
$1.00 \mathrm{E}+07$ & $1.00 \mathrm{E}+12$ & 0.00001 & 2.71414 & $2.78 \mathrm{E}-04$ & $2.75 \mathrm{E}+00$ & 1.24 \\
$1.00 \mathrm{E}+07$ & $1.00 \mathrm{E}+11$ & 0.0001 & 2.71408 & $2.57 \mathrm{E}-05$ & $2.75 \mathrm{E}+00$ & 1.24 \\
$1.00 \mathrm{E}+07$ & $1.00 \mathrm{E}+10$ & 0.001 & 2.71352 & $2.49 \mathrm{E}-06$ & $2.75 \mathrm{E}+00$ & 1.26 \\
$1.00 \mathrm{E}+07$ & $1.00 \mathrm{E}+09$ & 0.01 & 2.70822 & $2.76 \mathrm{E}-07$ & $2.75 \mathrm{E}+00$ & 1.45 \\
$1.00 \mathrm{E}+07$ & $1.00 \mathrm{E}+08$ & 0.1 & 2.67125 & $4.46 \mathrm{E}-08$ & $2.75 \mathrm{E}+00$ & 2.80 \\
$1.00 \mathrm{E}+07$ & $1.00 \mathrm{E}+07$ & 1 & 2.58677 & $3.29 \mathrm{E}-08$ & $2.75 \mathrm{E}+00$ & 5.87 \\
$1.00 \mathrm{E}+07$ & $1.00 \mathrm{E}+06$ & 10 & 2.51914 & $3.53 \mathrm{E}-08$ & $2.75 \mathrm{E}+00$ & 8.33 \\
\hline
\end{tabular}

The data given in table 4.4 and 4.5 is illustrated in figure 4.13

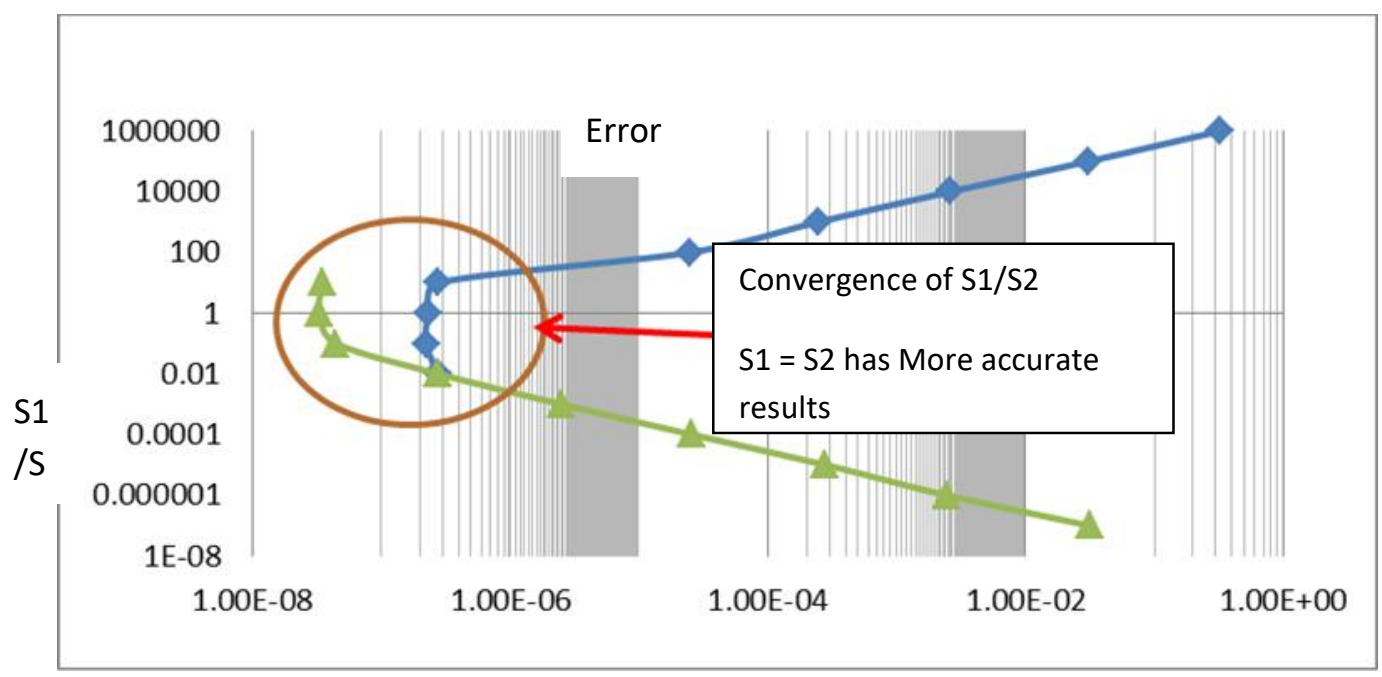

Fig.4.13. Relation between S1/S2 and Error for two story frame

Figure 4.13 shows clearly that $\mathrm{S} 1 / \mathrm{S} 2$ converges in the range of $0.1-10$ in logarithmic scale; same results have gotten from 1 and 3 story frames also. So we use S1/S2equal to 1 in order to take acceptable results with controlled Error. Now we can input the same values of S1 and S2 incrementally step by step into joint stiffness settings as shown in figure 4.9 in order to reach to stiffness convergence. It means that in a certain amount of rigidity, the frequency derived should 
be same as fundamental frequency which is calculated by software in rigid connection state as given in table 4.13 .

\section{RESULTS}

\section{Rigid Connection Frames}

After complete the modeling using procedure mentioned in pervious chapters now we can run the models. Varieties of models as described in table 4.1 have analyzed. In this part the results of non-castled moment resistance steel frames and semi-rigid frames will be presented.

Table 4.7. First Mode Frequency of Rigid Connection Steel Frames

\begin{tabular}{lllll}
\hline $\begin{array}{l}\text { Number of } \\
\text { Stories }\end{array}$ & $\begin{array}{l}\text { Total Frame } \\
\text { height }(\mathrm{m})\end{array}$ & $\begin{array}{l}\text { No } \\
\text { Bays }\end{array}$ & $\begin{array}{l}\text { of } \\
\text { Type }\end{array}$ & $f 1(\mathrm{~Hz})$ \\
\hline 1 & 3 & $3 \times 3$ & Rigid & 5.71326 \\
2 & 6 & $3 \times 3$ & Rigid & 2.45073 \\
3 & 9 & $3 \times 3$ & Rigid & 1.50588 \\
4 & 12 & $3 \times 3$ & Rigid & 1.13587 \\
5 & 15 & $3 \times 3$ & Rigid & 0.875367 \\
6 & 18 & $3 \times 3$ & Rigid & 0.809366 \\
7 & 21 & $3 \times 3$ & Rigid & 0.707011 \\
\hline
\end{tabular}

Table 4.8. First Mode Frequency of Rigid Connection Steel Frames

\begin{tabular}{llllll}
\hline Number of & $\begin{array}{l}\text { Total } \\
\text { height }(\mathrm{m})\end{array}$ & Frame & $\begin{array}{l}\text { No } \\
\text { Bays }\end{array}$ & & \\
& & & & \\
\hline 1 & 3 & $1 \times 31(\mathrm{~Hz})$ & Rigid & 6.13193 \\
2 & 6 & $1 \times 3$ & Rigid & 2.55639
\end{tabular}




$\begin{array}{lllll}3 & 9 & 1 \times 3 & \text { Rigid } & 1.57833 \\ 4 & 12 & 1 \times 3 & \text { Rigid } & 1.18565 \\ 5 & 15 & 1 \times 3 & \text { Rigid } & 0.913901 \\ 6 & 18 & 1 \times 3 & \text { Rigid } & 0.740397 \\ 7 & 21 & 1 \times 3 & \text { Rigid } & 0.620797\end{array}$

Table 4.9. First Mode Frequency of Rigid Connection Steel Frames

\begin{tabular}{|c|c|c|c|c|}
\hline $\begin{array}{l}\text { Number of } \\
\text { Stories }\end{array}$ & $\begin{array}{l}\text { Total Frame } \\
\text { height }(\mathrm{m})\end{array}$ & $\begin{array}{l}\text { No of } \\
\text { Bays }\end{array}$ & $\begin{array}{l}\text { Connection } \\
\text { Type }\end{array}$ & $f 1(H z)$ \\
\hline 1 & 5 & $1 \times 3$ & Rigid & 2.98237 \\
\hline 2 & 10 & $1 \times 3$ & Rigid & 1.30946 \\
\hline 3 & 15 & $1 \times 3$ & Rigid & 0.815977 \\
\hline 4 & 20 & $1 \times 3$ & Rigid & 0.611291 \\
\hline
\end{tabular}

Table 4.10. First Mode Frequency of Rigid Connection Steel Frames

\begin{tabular}{lllll}
\hline $\begin{array}{l}\text { Number of } \\
\text { Stories }\end{array}$ & $\begin{array}{l}\text { Total Frame } \\
\text { height }(\mathrm{m})\end{array}$ & $\begin{array}{l}\text { No } \\
\text { Bays }\end{array}$ & $\begin{array}{l}\text { of } \\
\text { Type }\end{array}$ & $f 1(\mathrm{~Hz})$ \\
\hline 1 & 5 & $3 \times 3$ & Rigid & 2.7895 \\
2 & 10 & $3 \times 3$ & Rigid & 1.26252 \\
3 & 15 & $3 \times 3$ & Rigid & 0.785642 \\
4 & 20 & $3 \times 3$ & Rigid & 0.590378
\end{tabular}




\begin{tabular}{|c|c|c|c|c|}
\hline 5 & 25 & $3 \times 3$ & Rigid & 0.4577 \\
\hline 6 & 30 & $3 \times 3$ & Rigid & 0.372785 \\
\hline 7 & 35 & $3 \times 3$ & Rigid & 0.31536 \\
\hline \multicolumn{5}{|c|}{ Table 4.11. First Mode Frequency of Rigid Connection Steel Frames } \\
\hline Number of & Frame & No of & Connection & \\
\hline Stories & height (m) & Bays & Туре & \\
\hline 1 & 5 & $1 \times 1$ & Rigid & 6.54683 \\
\hline 2 & 10 & $1 \times 1$ & Rigid & 2.74812 \\
\hline 3 & 15 & $1 \times 1$ & Rigid & 1.7055 \\
\hline 4 & 20 & $1 \times 1$ & Rigid & 1.2671 \\
\hline
\end{tabular}

Table 4.12. First Mode Frequency of 1:15 model

\begin{tabular}{lllll}
\hline $\begin{array}{l}\text { Number of } \\
\text { Stories }\end{array}$ & $\begin{array}{l}\text { Total Frame } \\
\text { height }(\mathrm{m})\end{array}$ & $\begin{array}{l}\text { No } \\
\text { Bays }\end{array}$ & $\begin{array}{l}\text { of } \\
\text { Type }\end{array}$ & $f 1(\mathrm{~Hz})$ \\
\hline 1 & 0.362 & $1 \times 1$ & Rigid & 57.9701 \\
2 & 0.617 & $1 \times 1$ & Rigid & 38.2758 \\
3 & 0.9 & $1 \times 1$ & Rigid & 28.919 \\
4 & 1.211 & $1 \times 1$ & Rigid & 23.324 \\
\hline
\end{tabular}

Small 1:15 frame was modeled based on specifications given in table 4.2 and chapter 4.8.2. 
Table 4.13. First Mode Frequency of Rigid Connection Steel Frames

\begin{tabular}{lllll}
\hline Number of & $\begin{array}{l}\text { Total Frame } \\
\text { height }(\mathrm{m})\end{array}$ & $\begin{array}{l}\text { No } \\
\text { Bays }\end{array}$ & $\begin{array}{l}\text { of } \\
\text { Type }\end{array}$ & $f 1(\mathrm{~Hz})$ \\
\hline 1 & 3 & $1 \times 1$ & Rigid & 6.54683 \\
2 & 6 & $1 \times 1$ & Rigid & 2.74812 \\
3 & 9 & $1 \times 1$ & Rigid & 1.7055 \\
4 & 12 & $1 \times 1$ & Rigid & 1.2671 \\
\hline
\end{tabular}

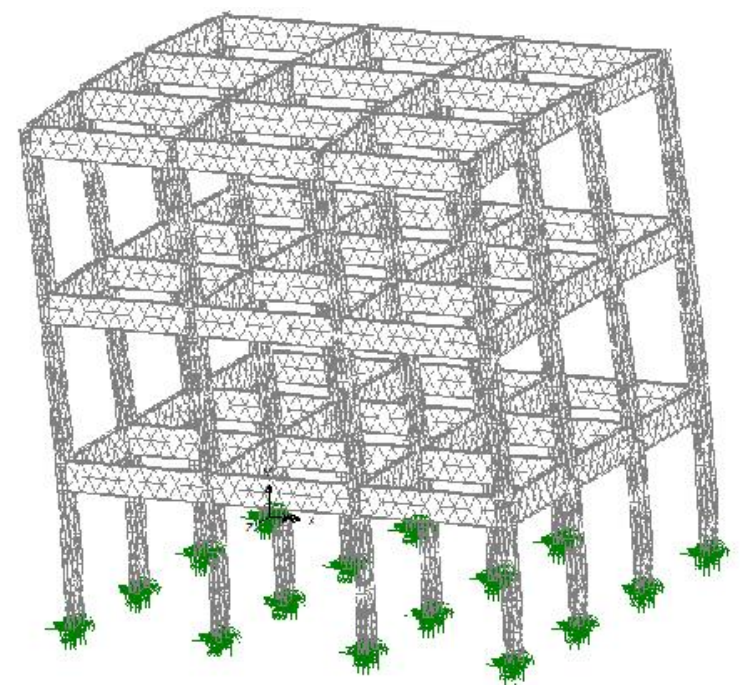

Fig.4.14. Deformed shape of Rigid Connection Steel Frame

\section{Model validation}

\section{Small 1:15 Model}

In order to find out that the model is able to calculate dynamic characteristics of steel frames, a small-scale (1:15) 3-storey moment resisting steel frame was modeled as mentioned in part 4.8.2 and the fundamental frequencies calculated. Figure 4.15 shows first mode shape on eigenvalue analysis under frame self-weight. 

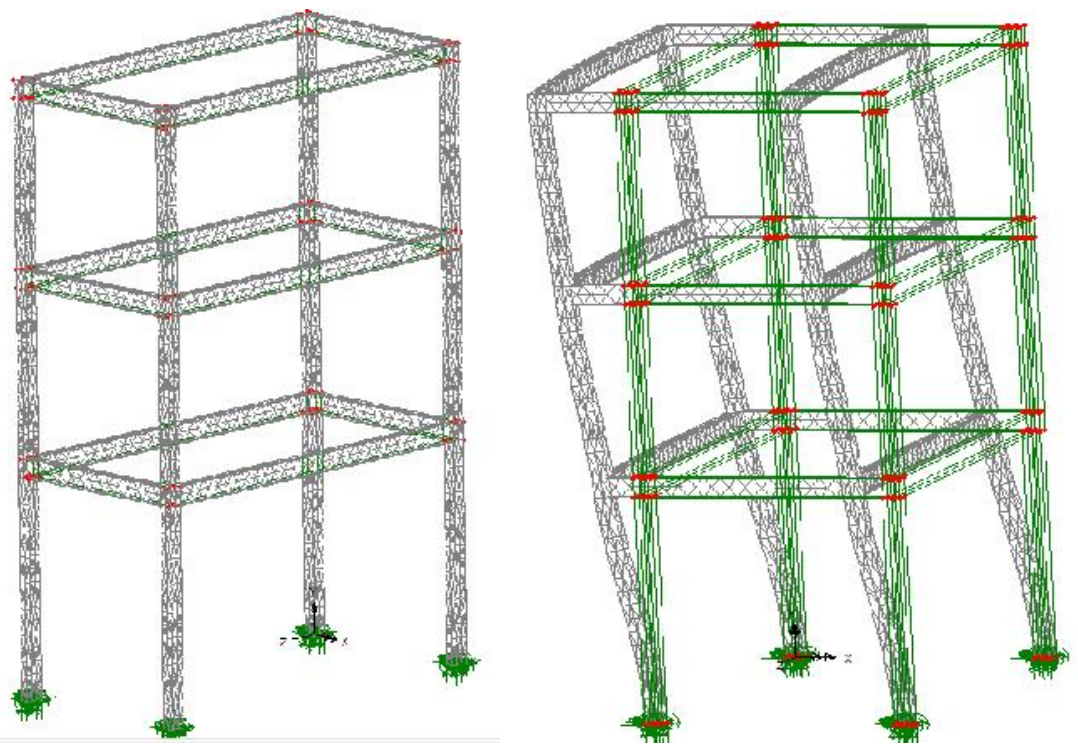

Fig.4.15. Unreformed and Deformed Shape of Small 1:15 Models Under Self-Weight In Eigenvalue Analysis

Table 4.14 shows comparison between analyzed model and Experimental results in Cinitha.A and Rama Raju (2008)

Table 4.15. First Mode Frequency Comparison 1:15 small Model Cinitha.A and Rama Raju Cinitha.A and Rama Raju LUSAS Model Which Is (2008) (2008) Used In This Study

Experimental

Ansys Model

$29.78 \mathrm{~Hz}$ 32.27 $28.919 \mathrm{~Hz}$

Comparing experimental frequency with analyzed frequency by LUSAS we can see the Error is only $3 \%$ while the result calculated by ANSIS has $8 \%$ error. So LUSAS model is capable to calculate fundamental frequency of the frame with acceptable accuracy.

\section{Mathematical Calculations}

As ASCE/SEI 7-05 proposes in Equivalent Lateral Force Procedure fundamental period (Ta) of a structure in the specific direction can be determined using the following equation: 
$T_{a}=C_{t} h_{n}^{x}$

where $h_{n}$ is the height above the base to the highest level of the structure; $\mathrm{Ct}=0.0724$ for steel Moment-Resisting Frames, 0.0466 for Reinforced Concrete Moment-Resisting frames, and $\mathrm{x}$ $=0.8$ for steel moment-resisting frames, 0.9 for reinforced concrete moment-resisting frames. The Uniform Building Code (UBC) has proposed procedure named as Static Force two methods for calculation of fundamental period (T), Method A and Method B.

In method A an approximated formula as bellow is given:

$T=C_{t}\left(h_{n}\right)^{3 / 4}$

Where $\mathrm{Ct}=0.0853$ for steel moment-resisting frames and 0.0731 for reinforced concrete moment-resisting frames.

In Method B a formula based on the structural properties and deformation resisting of elements is proposed which is more accurate in comparison with Method A but more difficult to apply:

$$
\begin{aligned}
& T=2 \pi \sqrt{\left(\sum_{i=1}^{n} w_{i} \delta_{i}^{2}\right) \div\left(g \sum_{i=1}^{n} f_{i} \delta_{i}\right)} \\
& F_{x}=\left(\frac{w_{x} h_{x}^{k}}{\sum_{i=1}^{n} w_{i} h_{i=1}^{k}}\right)(V)
\end{aligned}
$$

Where:

$w_{i}=$ The portion of the total seismic dead load located at or assigned to level $\mathrm{i}$.

$\delta \mathrm{i}=$ the horizontal displacement at level $\mathrm{i}$ relative to the base due to applied lateral forces.

$\mathrm{g}=$ the acceleration due to gravity

$f_{i}=$ The lateral force at level i

$\mathrm{Fx}=$ the lateral force induced at level $\mathrm{x}$ of the frame, $w_{i}, w_{x}$ are the portion of the total gravity load of the structure assigned to level i or x, respectively, $h_{i}, h_{x}$ are the height from the base to level $\mathrm{i}$ or $\mathrm{x}$, respectively, $\mathrm{k}$ is a distribution exponent related to the frame period, $\mathrm{k}=1$ for 
a frame having a period of 0.5 second or less and $\mathrm{V}$ is the total design lateral force or shear at the base of the frame.

Although Eq.( 4.3) is not commonly used by structural engineers because the applied lateral force and the horizontal displacement at each level of the frame are required although it is more accurate in comparison with Eq.( 4.2) and (3.3).

Example 1: Compute the fundamental period of the three-story frame shown in Fig $4.16 \mathrm{We}$ assume that the beams are rigid (i.e., the flexural rigidity $=\infty$ for each beam). The moment of inertia about the $\mathrm{x}$-axis is Ix $=10300 \mathrm{~mm} 4$ for the columns and is Ix $=9540 \mathrm{~mm} 4$ for the beams. The modulus of elasticity is $\mathrm{E}=2.09(10 \mathrm{E}+5) \mathrm{MPa}$ for all columns

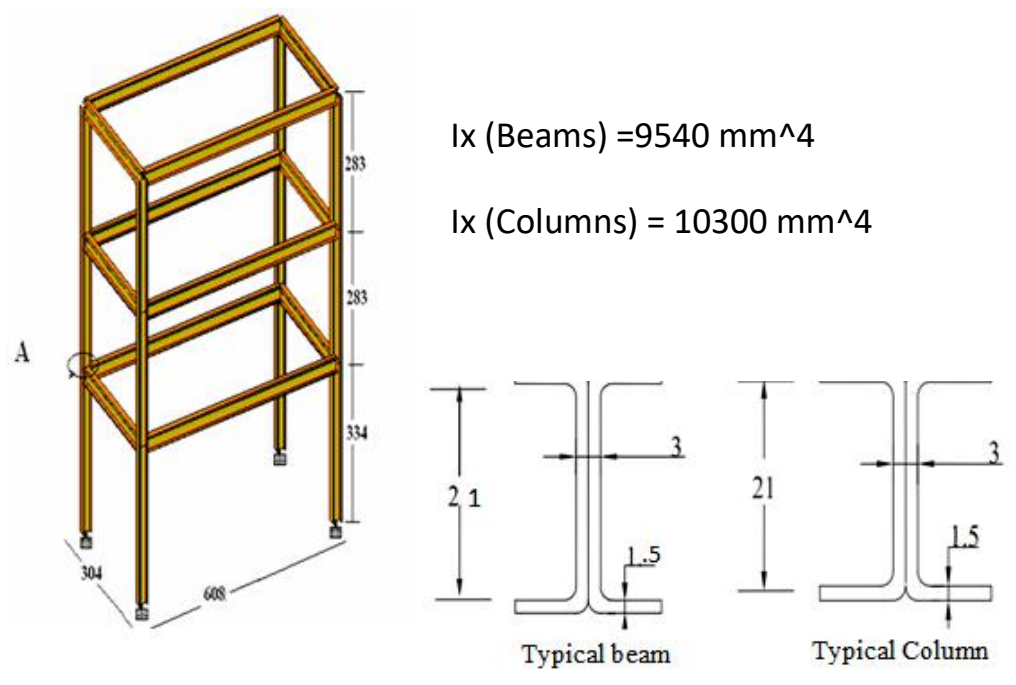

Fig.4.16. Small 1:15 Frame details

We want to consider the weight of frame as the only applied load we have to calculate the weight of each floor and concentrate it to related beam. Flexural deformation of column between rigid beams has shown in figure 4.3.2, this formula will give us the displacement caused by $\mathrm{F}$ in a 2D frame. In order to simplify the calculations model considered as a 2D frame. 


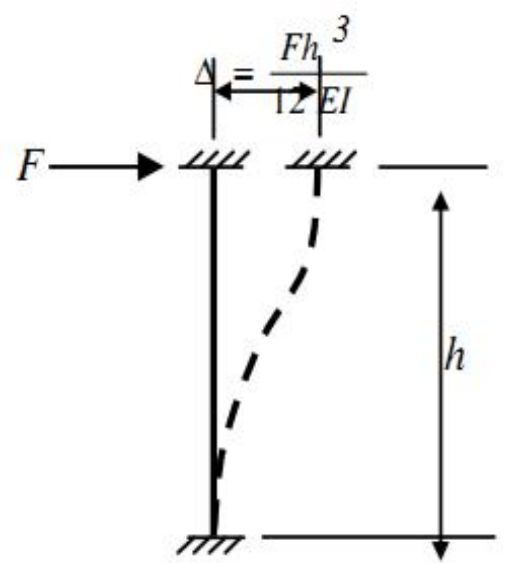

Fig.4.17. Flexural Deformation of column between rigid beams

Before calculation the $\Delta$ amount of $\mathrm{V}$ should be assumed as Total Design Lateral Force. Any amount of $\mathrm{V}$ can give same results we assume $V=100 \mathrm{KN}$. Using equations (4.4) we will have:

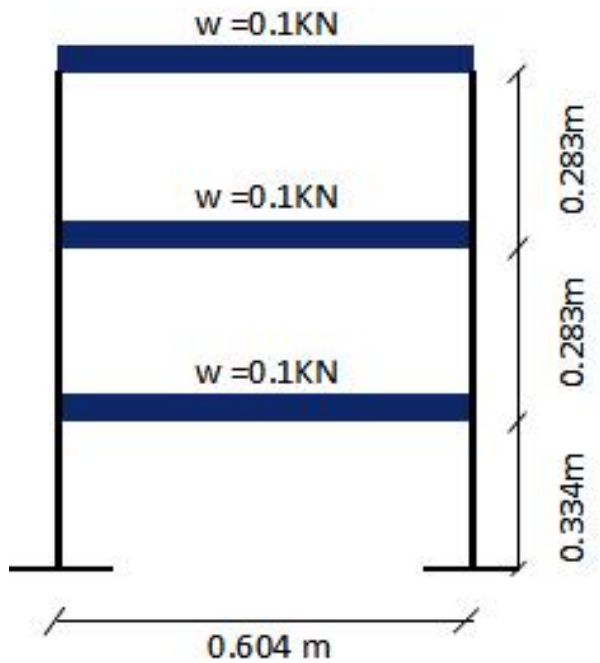

Fig.4.18. two dimensions Frame 
Table 4.16 Computation of the vertical distribution of seismic force

\begin{tabular}{lccccc}
\hline Level $x$ & $h_{x}(m)$ & $w_{x}(K N)$ & $h_{x} w_{x}$ & $\frac{h_{x} w_{x}}{\sum h_{i} w_{i}}$ & $F_{x}(K N)$ \\
& & & & & \\
\hline 3 & 0.90 & 0.1 & 0.090 & 0.4848 & 48.6150 \\
2 & 0.617 & 0.1 & 0.0617 & 0.3323 & 33.3283 \\
1 & 0.334 & 0.1 & 0.0334 & 0.1829 & 18.0566 \\
Total: & & & & & 100.00 \\
\hline
\end{tabular}

$\Delta_{1}=\frac{\left(F_{1}+F_{2}+F_{3}\right) h^{3}}{12 E I_{x}}=\frac{(100 \times 1000 N) \times(334 \mathrm{~mm})^{3}}{12(209000)(2 \times 10300)}=72.1 \mathrm{~mm}$

$\Delta_{2}=\frac{\left(F_{2}+F_{3}\right) h^{3}}{12 E I_{x}}=\frac{(81.7106 \times 1000 \mathrm{~N}) \times(283 \mathrm{~mm})^{3}}{12(209000)(2 \times 10300)}=35.9 \mathrm{~mm}$

$\Delta_{3}=\frac{\left(F_{3}\right) h^{3}}{12 E I_{x}}=\frac{(48 . .4770 \times 1000 \mathrm{~N}) \times(283 \mathrm{~mm})^{3}}{12(209000)(2 \times 10300)}=21.3 \mathrm{~mm}$

Table 4.17. Computation of $w_{i} \delta_{i}{ }^{2}$ and $f_{i} \delta i$

\begin{tabular}{lccccc}
\hline Level.i & $W_{i}(\mathrm{KN})$ & $F_{i}(\mathrm{KN})$ & $\delta_{i}(\mathrm{~mm})$ & $w_{i} \delta_{i}{ }^{2}\left(\mathrm{KN} . \mathrm{mm}^{2}\right)$ & $f_{i} \delta_{i}\left(K N . \mathrm{mm}^{2}\right)$ \\
\hline 3 & 0.1 & 48.615 & 12.91 & 1674 & 6290.482105 \\
2 & 0.1 & 33.3283 & 10.80 & 1176 & 360.672998 \\
1 & 0.1 & 18.0566 & 72.10 & 520 & 1302.211594 \\
Total: & & & & 3361 & 11194.3667 \\
\hline
\end{tabular}


Using Equation (3) we will have:

$$
T=2 \pi \sqrt{\frac{3361 K N . m^{2}}{\frac{9810 m m}{S e c^{2}}(11194.3667 K N . m m)}}=0.03476 \mathrm{Sec}
$$

$F_{1}=1 / T=28.76879(H z)$

The result calculated by LUSAS as mentioned in table 4.15 is $28.919 \mathrm{~Hz}$ which is so close to hand calculated fundamental frequency.

Example 2: Compute the fundamental period of the 3-story 3-Span frame shown in Fig 4.19(Bellow) We assume that the beams are rigid (i.e., the flexural rigidity $=\infty$ for each beam). The moment of inertia about the $\mathrm{x}$-axis is $\mathrm{Ix}=3.33 \mathrm{E}+8 \mathrm{~mm} 4$ for the columns $\mathrm{W} 18 \mathrm{x} 49$ and is $\mathrm{Ix}=6.49 \mathrm{E}+8 \mathrm{~mm} 4$ for the beams W24x62. The modulus of elasticity is $\mathrm{E}=2.09(10 \mathrm{E}+5)$ MPa for all columns.

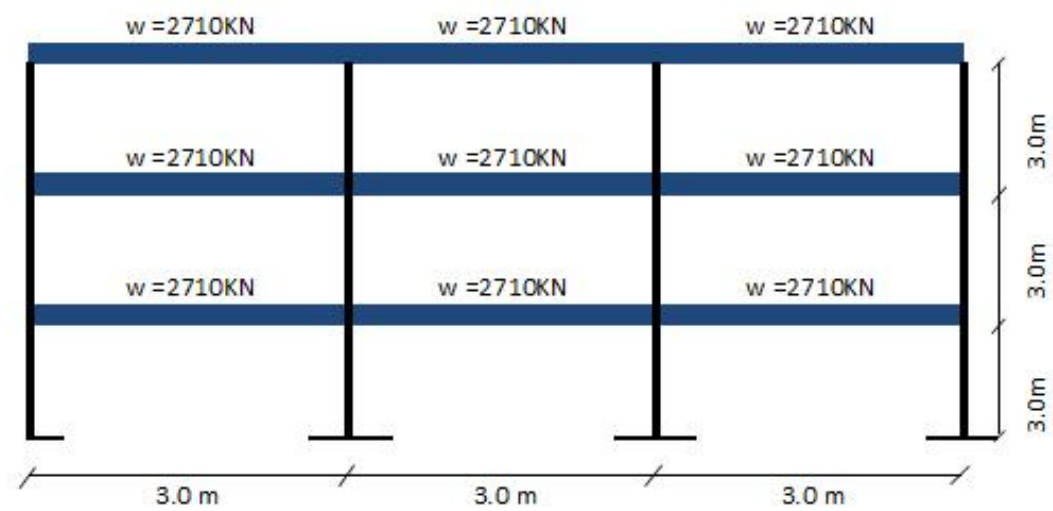

Fig.4.19. Three story-three span Steel frame as modeled in LUSAS

Amount of Load calculated by considering the weight of W24x63 as the only load applied to frame.

To calculation the $\Delta$ amount of $\mathrm{V}$ should be assumed as Total Design Lateral Force. Any amount of $\mathrm{V}$ can give same results we assume $V=100 \mathrm{KN}$. Using equations (4.4) we will have: 
Table 4.18. Computation of the vertical distribution of seismic force

\begin{tabular}{lccccc}
\hline Level $x$ & $h_{x}(m)$ & $w_{x}(K N)$ & $h_{x} w_{x}$ & $\frac{h_{x} w_{x}}{\sum h_{i} w_{i}}$ & $F_{x}(K N)$ \\
& & & & & \\
\hline 3 & 9.0 & 2710 & 24392 & 0.5000 & 50.00 \\
2 & 6.0 & 2710 & 16261 & 0.3333 & 33.3333 \\
1 & 3.0 & 2710 & 8131 & 0.1667 & 16.6667 \\
Total: & & & & & 100.00 \\
\hline
\end{tabular}

$\Delta_{1}=\frac{\left(F_{1}+F_{2}+F_{3}\right) h^{3}}{12 E I_{x}}=\frac{(100 \times 1000 \mathrm{~N}) \times(30000 \mathrm{~mm})^{3}}{12(209000)(4 \times 3.33 E+8)}=0.81 \mathrm{~mm}$

$\Delta_{2}=\frac{\left(F_{2}+F_{3}\right) h^{3}}{12 E I_{x}}=\frac{(83.3333 \times 1000 \mathrm{~N}) \times(3000 \mathrm{~mm})^{3}}{12(209000)(2 \times 3.33 E+8)}=1.48 \mathrm{~mm}$

$\Delta_{3}=\frac{\left(F_{3}\right) h^{3}}{12 E I_{x}}=\frac{(50 \times 1000 \mathrm{~N}) \times(3000 \mathrm{~mm})^{3}}{12(209000)(4 \times 3.33 E+8)}=1.89 \mathrm{~mm}$

Using Equation (3) we will have:

$$
T=2 \pi \sqrt{\frac{17361 K N . m^{2}}{\frac{9810 m m}{S e c^{2}}(157 K N . m m)}}=0.666727 \mathrm{Sec}
$$


Table 4.19. Computation of $w_{i} \delta_{i}{ }^{2}$ and $f_{i} \delta i$

\begin{tabular}{lccccc}
\hline Level. $i$ & $W_{i}(K N)$ & $F_{i}(K N)$ & $\delta_{i}(\mathrm{~mm})$ & $w_{i} \delta_{i}{ }^{2}\left(K N . m^{2}\right)$ & $f_{i} \delta_{i}\left(K N . m^{2}\right)$ \\
\hline 3 & 2710 & 50.0000 & 1.89 & 9640 & 94.30 \\
2 & 2710 & 33.3333 & 1.48 & 5951 & 49.393700 \\
1 & 2710 & 16.6667 & 0.808 & 1771 & 13.471000 \\
Total: & & & & 17361 & 157
\end{tabular}

And the fundamental frequency will be:

$F_{1}=1 / T=1.499865(H z)$

The result calculated by LUSAS model which is mentioned in Table 4.7 is $1.50588(\mathrm{~Hz})$ which is again so close to hand calculated result.

A comparison between LUSAS Results and hand calculation results has been given in table 4.20

Table 4.20 Comparison between F1 calculated by LUSAS and Method B

\begin{tabular}{llll}
\hline No of Story & $\begin{array}{l}\text { F1 Calculated } \\
\text { LUSAS }\end{array}$ & $\begin{array}{l}\text { by } \\
\text { method B (UBC) }\end{array}$ \\
\hline 7 & 0.707011 & 0.704585 \\
6 & 0.809366 & 0.81248 \\
5 & 0.875367 & 0.905623 \\
4 & 1.13587 & 1.170476 \\
3 & 1.50588 & 1.499865 \\
\hline
\end{tabular}




\section{Comparison with Numerical Results}

Fundamental frequencies obtained from ANSYS which is mentioned in Cinitha.A and Rama Raju (2008) is now going to be verified and compared with the result calculated by LUSAS. This comparison is given in tablec4.21 and figure 4.20.

Table 4.21 Comparison between Paper results and LUSAS model

\begin{tabular}{|c|c|c|c|c|c|c|c|}
\hline Story & No of & Plan & Span & Beam & Column & F1 calculated & F1 \\
\hline Height & Stories & Ratio & Length & Section & Section & by LUSAS & Calculated by \\
\hline (m) & & & $(\mathrm{mm})$ & & & model & Cinitha.A \\
\hline & & & & & & (As table 4.6) & and Rama \\
\hline & & & & & & & Raju (2008) \\
\hline 6 & 2 & $3 \times 3$ & 3000 & W24x80 & W18x50 & 2.4573 & 2.5 \\
\hline 9 & 3 & $3 \times 3$ & 3000 & W24x 80 & W18x50 & 1.50588 & 1.5 \\
\hline 12 & 4 & $3 \times 3$ & 3000 & W24x 80 & W18x50 & 1.13587 & 1.1 \\
\hline 15 & 5 & $3 \times 3$ & 3000 & $\mathrm{~W} 24 \times 80$ & W18x50 & .875367 & 0.85 \\
\hline 18 & 6 & $3 \times 3$ & 3000 & W24x80 & W18x50 & 0.809366 & 0.75 \\
\hline 21 & 7 & $3 \times 3$ & 3000 & W24x80 & W18x50 & 0.707011 & 0.60 \\
\hline
\end{tabular}

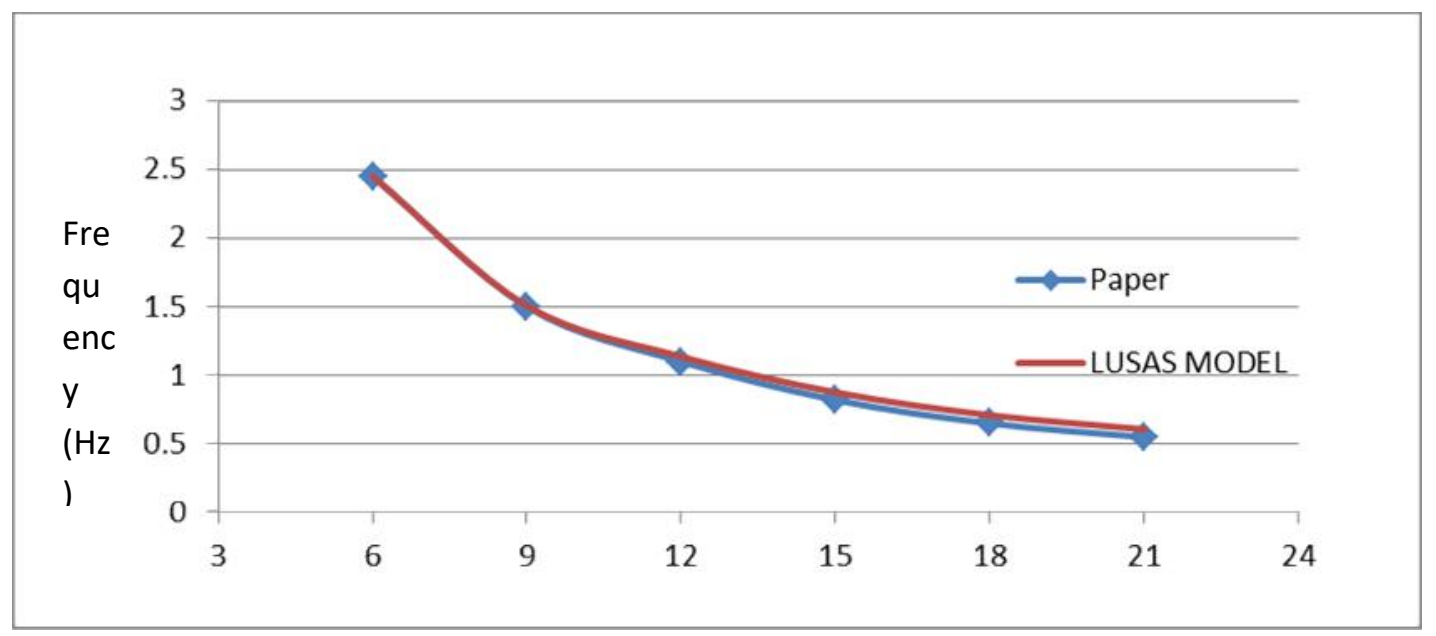

Fig.4.20. Comparison between Paper results and LUSAS model Height of frame $(m)$ 
Although results are almost same, seems that by increasing the frame height difference will increases. But in height range that we are going to focus in this study the accuracy of results is satisfying. Beside since the aim of this study is to evaluate the effect of castling on steel frames, and the results of castled model will be compared by its own non castled model, any difference and error will be eliminated.

\section{Semi-rigid Model verification}

Semirigid frames are frames which beam-to-column joints are neither pinned nor rigid. In reality all frames are semi because perfect pinned or rigid joints do not exist. However, for design purposes if the amount of moment that can be transmitted by the joint is small, the joint can be idealized as pinned, and if the moment that can be transmitted be large, the joint can be assumed as rigid.

There are two classification systems have been proposed for semirigid frames to separate them from rigid frames. The classification system by Bjorhovde and Colson (1990) which is based primarily on member response whereas the classification system by Eurocode 32 is based on overall frame response. Both systems classified connections in terms of their stiffness and strength. Boundary lines were established on the no dimensional connection momentrotation plots to identify regions in which joints were considered semirigid.

Figure 4.21 shows the semirigid frame model used in this study It has a beam with moment of inertia $I_{s}$ and length $L_{h}$, and two columns with moments of inertia I and lengths L, joined at $\mathrm{B}$ and $\mathrm{C}$ by two semirigid connections. The connections are modeled as rotational springs at the beam ends. We consider only moment-rotational mode of the connections. The axial and shear deformation modes of the connections are ignored. The frame is subjected to two types of loadings: a time- dependent lateral load $\mathrm{F}(\mathrm{t})$ and two time-independent gravity concentrated column loads $\mathrm{Pb}$ and $\mathrm{Pc}$ which can be considered as frame self-weight. Frame analyses under the combined effect of gravity and lateral loads are carried out using the stiffness matrix method. 


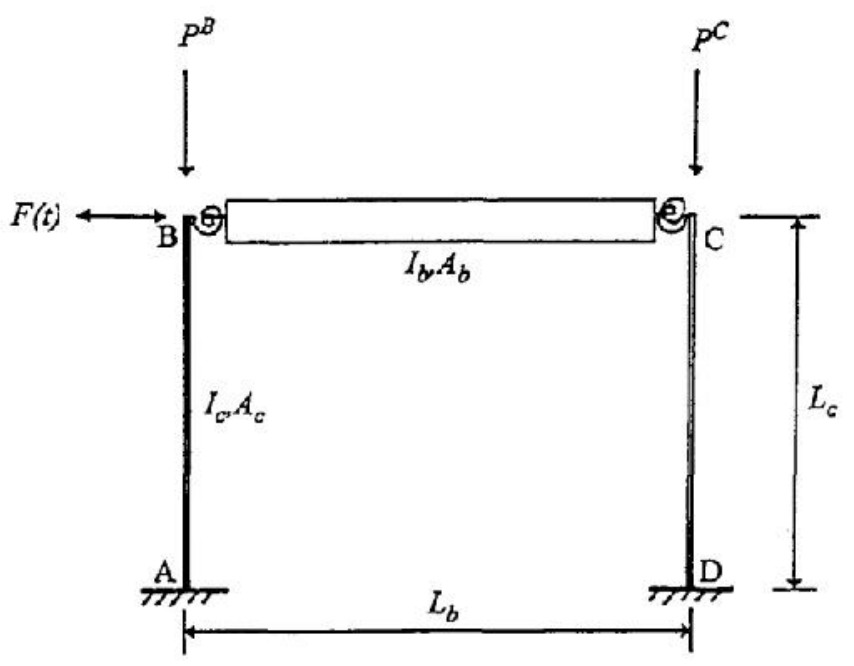

Fig.4.21. Parametric Description of Semirigid Frame

If we consider figure 4.22 as free body diagram of columns and joints we will have for semirigid frames:

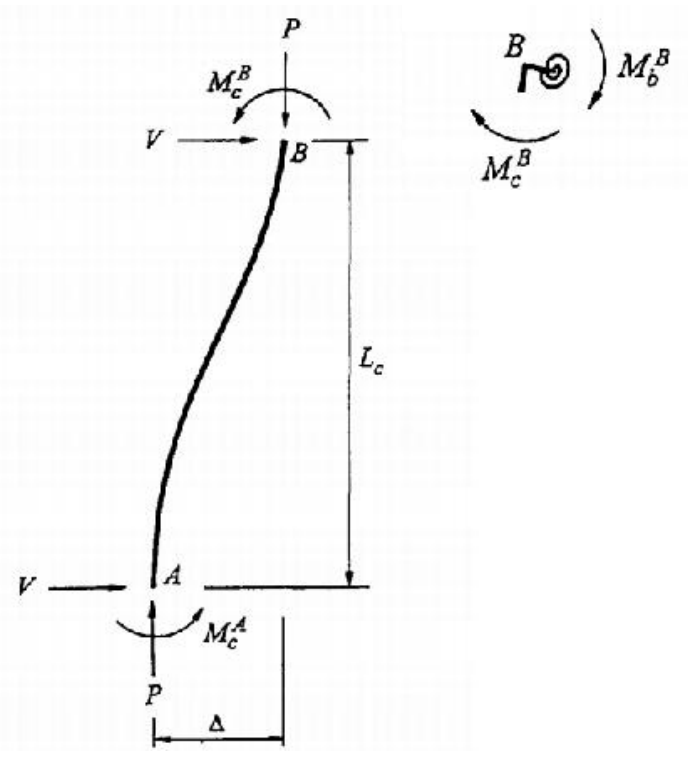

Fig.4.22. Free body diagrams of columns and joints 
$M_{C}^{A}+M_{C}^{B}-V L_{C}-P \Delta=0$

Which lateral column stiffness can be written as :

$K_{C}^{\text {lateral }}=\frac{V}{\Delta}=\frac{M_{C}^{A}-M_{C}^{B}}{L_{C} \Delta}-\frac{P}{L_{C}}$

It is proven by E. M. Lui and A. Lopes, $M_{C}^{A}$ and $M_{C}^{B}$ can be expressed in term of the column end displacements by assuming $M_{C}^{A}+M_{C}^{B}=0$ and considering axial force of column as a small value we will have:

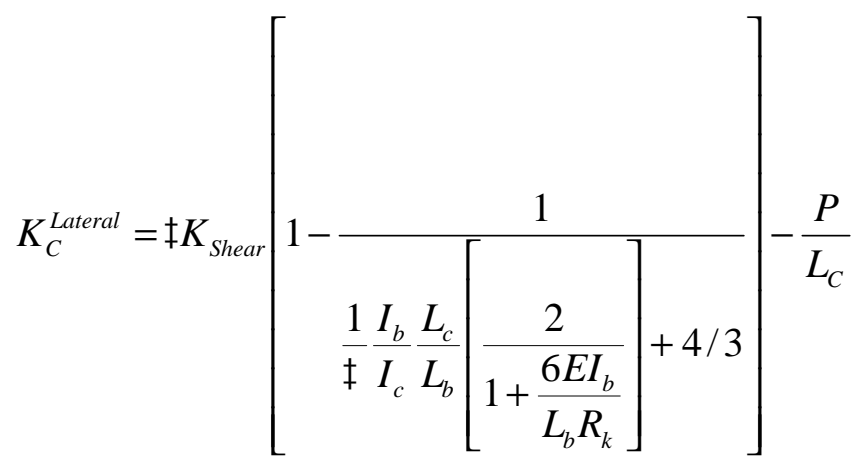

Where:

- $K_{\text {Shear }}=\frac{12 E I_{C}}{L_{C}^{3}}$ Is lateral column stiffness of a rigid connection and stiff beam.

- $\tau$ Is a factor which accounts for column inelasticity and It is defined as the ratio of the tangent modulus $E_{t}$ to the elastic modulus $\mathrm{E}$ of the column. In the present study, this modular ratio is approximated [20] by the expression. 
If $\frac{P}{P_{y}} \leq 0.39, \tau \approx 1$ and $\tau \approx-2.724 \frac{P}{P_{y}} \operatorname{Ln}\left(\frac{P}{P_{y}}\right)$ if else.

- $R_{K}$ is the stiffness of connection

The term in brackets is a stiffness reduction factor to account for the effect of beam and connection flexibilities and the term $\mathrm{P} / \mathrm{L}$ is a stiffness reduction factor to account for the effect of frame instability.

Using Eq. (3) if we assume that the P is much less than Py since we have no loading except frame weight in free vibration analysis, the P-Delta effect will be negligible and Eq. (3) will be simplified as:

$I_{C}^{\text {Lateral }}=I_{C}\left[1-\frac{1}{\frac{I_{b}}{I_{c}} \frac{L_{c}}{L_{b}}\left[\frac{2}{1+\frac{6 E I_{b}}{L_{b} R_{k}}}\right]+4 / 3}\right]$

So new moment of inertia of column will be calculated, now using same technique as mentioned for hand calculation of frequency for moment resistance steel frames we can calculate the natural period and fundamental frequency of MRF using modified Ic.

Also using try and error we can estimate the fixed connection capacity of the specific connection with specific beam and column section and materials.

Example 3: Determine fundamental frequency of steel frame given in Example 2 assuming semirigid connection of beam to column. Determine fully rigid connection stiffness.

Solution: 
In order to calculation the fundamental frequency of semirigid frame while the capacity of connection is not clear, first we have to estimate rigid connection stiffness using try and error technique in Equation (4) we will have:

I beam (mm4): 6.49E+08

L beam (mm): 3000

I column (mm4): 3.33E+08

L column (mm): 3000

E (Mpa): 2.09E+05

$\mathrm{Rk}(\mathrm{N}-\mathrm{mm} / \mathrm{Rad})$ : variable and wanted.

Using Equation (4) and $R_{k}=1.00 E+10(N . \mathrm{mm} / \mathrm{Rad})$

$I_{C}^{\text {Latteral }}=(3.33 E+08)\left[1-\frac{1}{\left.\frac{6.49 E+8}{3.33 E+8} \times \frac{3000}{3000}\left[\frac{2}{1+\frac{6(209)(6.49 E+8)}{3000 * 1.00 E+10}}\right]+\frac{4}{3}\right]}\right.$

$I_{c}^{\text {Lateral }}=268,065,962(\mathrm{~mm} 4)$

Which almost $81 \%$ is of $I_{x x}$ belong to W18x50.

Using calculated Ic and Equation 4.3.3 and 4.3.4 we will have: 
Table 4.21. Computation of the Vertical Distribution of Seismic Force

\begin{tabular}{lccccc}
\hline Level $x$ & $h_{x}(m)$ & $w_{x}(K N)$ & $h_{x} w_{x}$ & $\frac{h_{x} w_{x}}{\sum h_{i} w_{i}}$ & $F_{x}(K N)$ \\
& & & & & \\
\hline 3 & 9.0 & 2710 & 24,392 & 0.5000 & 50.0000 \\
2 & 6.0 & 2710 & 16,261 & 0.3333 & 33.3333 \\
1 & 3.0 & 2710 & 8,131 & 0.1667 & 16.6667 \\
Total: & & & & & 100.00 \\
\hline
\end{tabular}

$\Delta_{1}=\frac{\left(F_{1}+F_{2}+F_{3}\right) h^{3}}{12 E I_{x}}=\frac{(100 \times 1000 \mathrm{~N}) \times(3000 \mathrm{~mm})^{3}}{12(209000)(4 \times 268,065,962)}=1.00 \mathrm{~mm}$

$\Delta_{2}=\frac{\left(F_{2}+F_{3}\right) h^{3}}{12 E I_{x}}=\frac{(83.3333 \times 1000 \mathrm{~N}) \times(3000 \mathrm{~mm})^{3}}{12(209000)(4 \times 268,065,962)}=0.83 \mathrm{~mm}$

$\Delta_{3}=\frac{\left(F_{3}\right) h^{3}}{12 E I_{x}}=\frac{(50 \times 1000 \mathrm{~N}) \times(3000 \mathrm{~mm})^{3}}{12(209000)(4 \times 268,065,962)}=0.502 \mathrm{~mm}$

Table 4.22 Computation of $w_{i} \delta_{i}{ }^{2}$ and $f_{i} \delta i$

\begin{tabular}{llllll}
\hline Level.i & $W_{i}(\mathrm{KN})$ & $F_{i}(\mathrm{KN})$ & $\delta_{i}(\mathrm{~mm})$ & $w_{i} \delta_{i}{ }^{2}\left(K N . \mathrm{mm}^{2}\right)$ & $f_{i} \delta_{i}\left(K N . \mathrm{mm}^{2}\right)$ \\
\hline 3 & 2710 & 50.0000 & 2.34 & 14,874 & 117 \\
2 & 2710 & 33.3333 & 1.84 & 9,182 & 61.3556 \\
1 & 2710 & 16.6667 & 1 & 2,732 & 16.7333 \\
Total: & & & & 26,788 & 195 \\
\end{tabular}


Using Equation (3) we will have:

$$
T=2 \pi \sqrt{\frac{26788 K N . m^{2}}{\frac{9810 m m}{S e c^{2}}(195 K N . m m)}}=0.743086 \mathrm{Sec}
$$

$F_{1}=1 / T=1.345738(H z)$

As shown in example 2 the rigid connection fundamental frequency is 1.4999 but in semirigid connection the frequency reduced to $1.34574 \mathrm{~Hz}$. To evaluate the rigid connection using try and error table 4 has presented. Using different values of $R k \quad$ I lateral was calculated. The result calculated by LUSAS with same connection rigidity is $1.28337 \mathrm{~Hz}$ which has less than $5 \%$ error. Also fundamental frequency calculated by equivalent I presented in table 4 . It can be seen that maximum amount of I lateral is $81 \%$ which can give $90 \%$ of Rigid connection fundamental frequency.

Table 4.24. Connection Stiffness and Fundamental frequencies using Equation 4.4 in Three Story and Three Span Frame

\begin{tabular}{lllll}
\hline \multirow{2}{*}{$\mathrm{Rk}(\mathrm{N} . \mathrm{mm} / \mathrm{Rad})$} & $\mathrm{I}(\mathrm{mm} 4)$ & \multicolumn{3}{l}{$\mathrm{F} 1(\mathrm{~Hz})$} \\
\cline { 2 - 5 } & & & & \\
& & & & \\
& & & & \\
& & & & \\
$1.00 \mathrm{E}+16$ & 269343856 & $81 \%$ & 1.345738 & $90 \%$ \\
$1.00 \mathrm{E}+15$ & 269343845 & $81 \%$ & 1.345738 & $90 \%$ \\
$1.00 \mathrm{E}+14$ & 269343729 & $81 \%$ & 1.345738 & $90 \%$ \\
$1.00 \mathrm{E}+13$ & $269,342,571$ & $81 \%$ & 1.345738 & $90 \%$ \\
$1.00 \mathrm{E}+12$ & $269,330,991$ & $81 \%$ & 1.345738 & $90 \%$ \\
$1.00 \mathrm{E}+11$ & $269,215,273$ & $81 \%$ & 1.345738 & $90 \%$
\end{tabular}




$\begin{array}{lllll}1.00 \mathrm{E}+10 & 268,065,962 & 81 \% & 1.345738 & 90 \% \\ 1.00 \mathrm{E}+09 & 257,308,706 & 77 \% & 1.31846 & 88 \% \\ 1.00 \mathrm{E}+08 & 193,270,829 & 58 \% & 1.142676 & 76 \% \\ 1.00 \mathrm{E}+07 & 106,763,263 & 32 \% & 0.84928 & 57 \% \\ 1.00 \mathrm{E}+06 & 85,903,018 & 26 \% & 0.761805 & 51 \% \\ 1.00 \mathrm{E}+05 & 83,518,750 & 25 \% & 0.749951 & 50 \% \\ 1.00 \mathrm{E}+04 & 83,250,027 & 25 \% & 0.749949 & 50 \% \\ 1.00 \mathrm{E}+03 & 83,250,003 & 25 \% & 0.749949 & 50 \% \\ 1.00 \mathrm{E}+02 & 83,250,000 & 25 \% & 0.749949 & 50 \% \\ 1.00 \mathrm{E}+01 & 83,250,000 & 25 \% & 0.749949 & 50 \% \\ 1 & 83,250,000 & 25 \% & 0.749949 & 50 \%\end{array}$

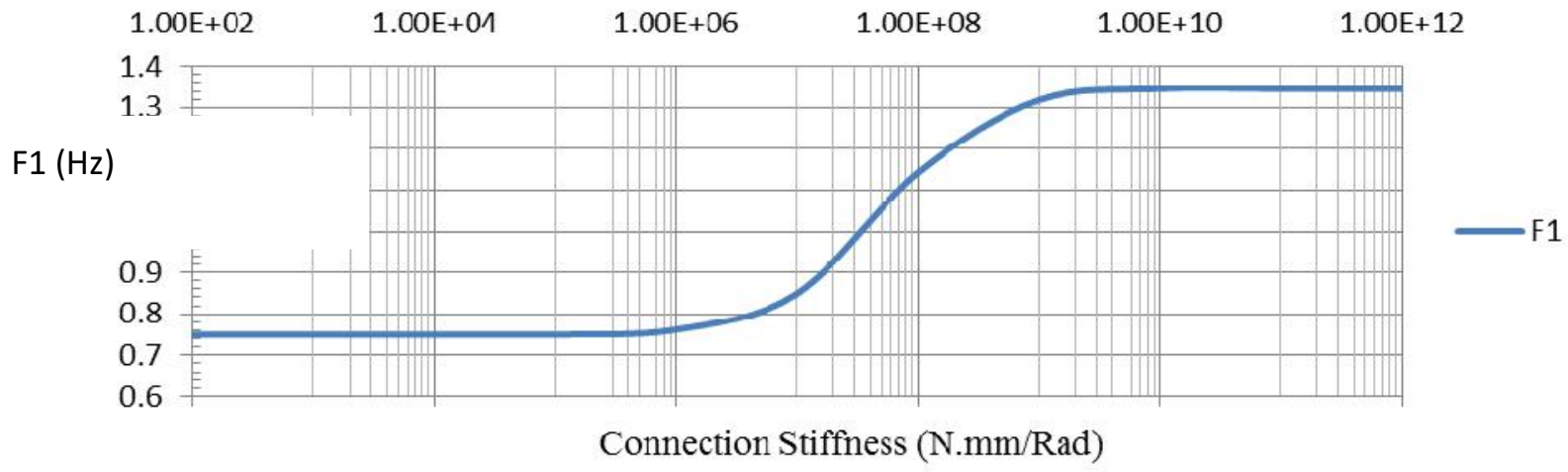

Fig.4.23. Connection Stiffness and Fundamental frequencies Using Equation 4.4 


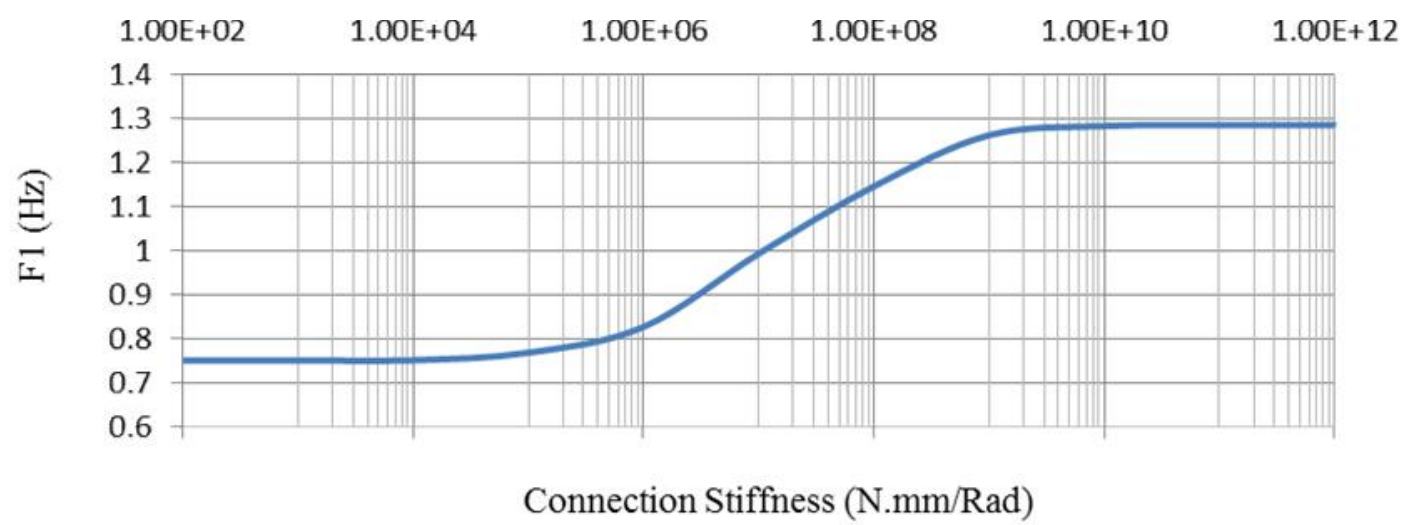

Fig.4.24. Connection Stiffness and Fundamental frequencies Using LUSAS Model

Connection stiffness convergence (not the frequency) shown in graphs above are free from frame height, story height, bay size or plan ratio but just beam and column sections and material properties. From mentioned graphs amount of $1.00 \mathrm{E}+10 \mathrm{~N} . \mathrm{mm} / \mathrm{Rad}$ can be extracted as fixed connection stiffness. $81 \%$ of moment of inertia can be calculated from another way. If we consider Equation (4) and input a big value as Rk we will have:

$I_{C}^{\text {Lateral }}=I_{C}\left[1-\frac{1}{2 \times \frac{I_{b}}{I_{c}} \frac{L_{c}}{L_{b}}+4 / 3}\right]$

$\% I_{0}=1-\frac{1}{2 \times \frac{I_{b}}{I_{c}} \frac{L_{c}}{L_{b}}+4 / 3}$

$\% I_{0}=1-\frac{1}{2 \times \frac{6.49}{3.33} \times \frac{3000}{3000}+4 / 3}=81 \%$

\section{CONCLUSION}

This chapter covered the specification and dimensions of steel frames which are studied include beam and column sections, number of stories, frame heights, story heights, bay size and plan ratios. Also defining surface mesh, material properties and supports were covered as well as the 
adjustment of eigenvalue settings. In continue a thorough description about elastic connection include procedure of modeling and input values added. Some examples about convergence studies and final results also have given. The final part of this chapter is verification of the results. Verification in this study done in three ways using experimental data available in references, numerical verified data which is given in references and mathematical calculations as mentioned in part 4.10 .

\section{REFERENCES}

1. Akash R.Joshi, Seismic analysis: static and dynamic method of analysis, PhD Thesis, Lamar University. Pro-quest

2. Al-Bermani FGA, Kitipornchai S. Elastoplastic nonlinear analy-sis of flexibly jointed space frames. J. Struct. Engng1992;118(1):108-27.

3. Al-Bermani FGA, Li B, Zhu K, Kitipornchai S. Cyclic and seis-mic response of flexibly jointed frames. Engng Struct.1994;16(9):249-55.

4. Ali Ugur Ozturk and Hikmet H. Catal, "Dynamic Analysis of Semi-Rigid Frames", Mathematical and Computational Applications, 10, No. 1,(2005.) pp. 1-8,

5. American Society of Civil Engineers (2006). ASCE standard, minimum design loads for buildings and other struc-tures (ASCE/SEI 7-05), American Society of Civil Engi-neers, Reston, Va.

6. Bjorhovde, R., Colson. A. and Brozzetti, J. A classification system for beam to column connections', ASCE, J. Struct. Engng 1990, 116, 3059-3076

7. Briseghella L, Majorana CE, Pellegrino C. Dynamic stability of elastic structures: a finite element approach. Comp ut Struct 1998;69:11 -25.

8. Chan SL. Nonlinear static and dynamic analysis of space frameswith semi-rigid connections. Int. J. of Space Struct.1993;8(4):261-9.

9. Chan SL. Vibration and modal analysis of steel frames with semi-rigid connections. Engng Struct. 1994;16(1):25-31.

10. Cinitha.A, Rama Raju. K \& Nagesh.R. Iyer. Evaluation of Free Vibration Characteristics of Steel Space Frames. The 12th International Conference of International Association for Computer Methods and Advances in Geomechanics (IACMAG) 1-6 October, 2008 Goa, India. 
11. Masih Izadi Niaki, Mahmood Reza Maheri, Moein Bagheri, OPTIMUM DESIGN OF 2D REINFORCED CONCRETE FRAMES USING A GENETIC ALGORITHM, THE TURKISH ONLINE JOURNAL OF DESIGN, ART AND COMMUNICATION (TOJDAC), August, 2016.

How to cite this article:

Bagheri M, Baharom S, Izadi Niaki M. A study on effects of castling on natural frequencies of $3 \mathrm{~d}$ un-damped steel fames using finite element method. J. Fundam. Appl. Sci., 2017, 9(1S), 9711006. 